\title{
Acknowledgements
}

The authors thank both Rhonda J. McGinnis and Kent Yates. Ms. McGinnis, currently a Graduate Assistant at the Indiana University School of Library and Information Science, provided able assistance in drawing the samples, mailing the paper-based survey and coding responses for all surveys. Mr. Yates, Manager of Computing and Network Resources, Graduate School of Library and Information Science, at the University of Illinois, implemented the distribution of the electronic survey.

\section{The Modern Language Association: Electronic and Paper Surveys of Computer-based Tool Use}

\author{
Debora Shaw ${ }^{*}$ \\ shawd@indiana.edu \\ Charles H. Davis \\ davisc@indiana.edu \\ School of Library and Information Science \\ Indiana University \\ Bloomington, IN 47405 \\ telephone: (812) 855-5113 \\ fax: (812) 855-6166
}

\begin{abstract}
Members of the Modern Language Association of America (MLA) were surveyed about their use of computer-based tools. A questionnaire was sent to 1,000 randomly-selected members in the U.S., with 500 sent via paper mail and 500 through electronic mail. Word processing, electronic mail, online catalogs, and the MLA International Bibliography were used heavily. Responses by the two subgroups differed significantly in several respects. Electronic full texts received substantially less use by both groups, especially those responding to the print survey. Major changes in research habits included
\end{abstract}

\footnotetext{
${ }^{*}$ To whom correspondence should be addressed.
} 
greater reliance on word processing and more work outside of libraries. Problems reported focused on access to computer-based resources, learning to use them, the need for instruction, and inconsistent interfaces. Finally, evidence strongly suggests that reliance solely on electronic surveys may produce misleading results.

\section{Introduction}

Word processing, bibliographic databases, electronic mail, electronic texts, and other computer-based research tools have great potential for humanities scholars. Just as scientific research has changed with the introduction of computer-based tools in the laboratory, so too, scholars in the humanities have seen changes in the amount and kinds of research they can accomplish as these tools become more readily available -- even unavoidable.

Although the study of such subjects as automated language processing began in the 1950s, interest in computer applications in humanities research started in earnest when the journal computers and the Humanities began publication in 1966. However, there have been relatively few studies of how humanities researchers adapt to and cope with changes in their research tools. Stover notes that humanities scholars "have regularly received 'bad press' ... Humanists, it is said, are resistant to the idea of using computers in research." (1992 p. 575) He goes on to observe that the stereotypes are proving wrong, and that computer-based research is finding an important place in humanities scholarship. Most reports emphasize examples of cutting-edge applications and challenges such as use of electronic texts with appropriate mark-up languages and retrieval systems for analytical research. The library is often called the humanities scholar's laboratory; but if the library is the primary workplace for humanities research in general, it is important to know more about how typical researchers, those not on the forefront in computer applications, are affected by computer-based tools.

\section{Review of previous research}

A review by Tibbo (1991) provides a useful summary of the challenges to integrating traditional scholarship with the new technologies. She classifies 
computer applications into three areas: 1) those that all scholars use, such as word processing or electronic mail; (2) general purpose technologies that humanists tailor to their materials, such as CAI (computer-assisted instruction) programs; and (3) technologies that have unique significance for humanistic research, such as concordance programs for literary studies." ( $p$. 288) The assertion that "all scholars use" word processing, electronic mail, and library online catalogs suggests an area for research into the impact and adoption of these technologies, because there is a general belief that humanities scholars are reluctant to use computer-based tools, and speculation abounds on this topic.

Baron's (1985) description of three concerns about computers and technology has struck a chord with many observers: concern about the elimination of nuance and judgment, loss of the centrality of texts, and fear that the humanities will be rendered irrelevant. Humanities scholars also differ from those in the sciences and social sciences in their information seeking. Stone (1982) noted their tendency to work alone and to avoid delegating literature searching; their need to browse; their need for special access points such as period, national trait, or theme; their considerable reliance on monographs; and their need for retrospective coverage. Watson-Boone's (1994) review reaffirms Stone's observations. Cool (1993) observed that the disinclination to delegate searching reflects "knowing the literature" as a defining aspect of professional identity.

Several studies have looked at automation in the library and its effects on research in the humanities. Sievert \& Sievert (1989) include interesting observations on the library as laboratory analogy, suggesting that some see it as a "nagging mother" reminding them of work that could be done better, or as a supply house from which they get materials for research. Wiberley (1991) reported that humanities scholars seldom used reference services; while they used online as well as card catalogs, they rarely had searches done on other machine-readable resources. Studies such as Katzen's (1985) in United Kingdom academic libraries and that by Krausse and Etchingham (1986) provide evidence of interest and some limited use of electronic resources by humanities scholars. The availability of relevant bibliographic databases on CD-ROM has virtually removed the user's (economic) costs of computer-based searching, 
resulting in enthusiastic acceptance; McClamroch et al. (1991), for example, were surprised by the favorable response to the WILSONDISC version of the MLA International Bibliography: "End-users appear to appreciate how easy it is to get a satisfactory number of citations using the compact disk index as compared to using the $M L A$ print index. We feel, however, that our findings may say less about the quality of this product than about the difficulty and the costs, in terms of time, of using the print index." ( $p .84)$

Some humanities scholars have also adopted non-library computer-based tools for research. Wiberley and Jones (1994) trace the evolution of interest in and acceptance of word processing, electronic mail, and other computer applications as well as online catalogs and database searching. over five years between 1987 and 1992 they saw some increased use of word processing and electronic mail, but still identified reluctance to adopt information technology among some of the eleven humanists they interviewed. Others have identified similar low levels of adoption of electronic mail. Pandit's (1992) interviews with 36 scholars found only two who used electronic mail, and a 1990 membership survey (with 16,503 responses) by the MLA found $18 \%$ using electronic mail/computer networks. Adams' and Bonk's (1995) survey of faculty at the SUNY graduate institutions, also conducted in 1990, found that humanities professors were much less likely to have microcomputers or network access from their offices, but their home computer ownership and network access were equivalent to that of faculty in other disciplines.

Looking at "the humanities" may introduce confounding variances among the many practices and expectations of the several disciplines. Attempts at conveying the broad picture often include individual discussions by specific discipline. For example, Tibbo (1991) reports on research in archaeology, Biblical and classical studies, history, literary text analysis, and philosophy; a special issue of Library Trends (Stover 1992) on "Electronic Information in the Humanities" has articles on history, religious studies, English and American literature, linguistics, art history, and musicology. Sometimes studies of one subject area are reported as representative of the humanities as a whole (Siegfried et al. 1993), an approach which risks generalizing beyond the group observed. Hopkins (1989) suggests that distinguishing researchers by frequency of use of primary sources also may be useful. 
Surveying the affected population is a common way of measuring diffusion of innovations and soliciting users' perspectives on such innovations. (Rogers 1971) While standard techniques have been developed for mail and telephone surveys (Dillman 1978), the emergence of electronic mail as a survey delivery method is new and relatively little-studied. (Sproull 1986, walsh et al. 1992). Concerns about surveys conducted by electronic mail include lack of anonymity of respondents, technical difficulties with e-mail, and questions about the representativeness of respondents compared with the population assumed to be surveyed. Conducting a survey by posting to distributions lists adds concerns about low response rates caused by the impersonal distribution method, lack of salience of the list for many subscribers, potential for multiple responses if the survey is posted to several lists, and potential confounding if list subscribers forward the survey to non-subscribers. ${ }^{* *}$

\section{Description of study}

In the fall of 1994 a 21 -item questionnaire on use of computer-based tools was sent to 1000 members of the Modern Language Association of America (MLA). The MLA was selected as the survey population because it represents a selfselected group who choose to support the creation of an important bibliographic resource -- the MLA International Bibliography. MLA members are among the most research-prone humanities scholars, and presumably represent a variety of research interests in language and literature studies. Survey recipients were randomly selected from the September 1994 "Directory" issue of PMLA, the Publications of the Modern Language Association. Only MLA members with U.S. addresses were chosen, both to provide a reasonably similar level of access to computing resources and to facilitate response by postage-paid envelope for the paper-based survey. Five hundred MLA members were sent the questionnaire via the U.S. Postal Service and 500 MLA members who had e-mail addresses listed in the Directory were sent an identical set of questions by electronic mail over the Internet or (in 22 cases) Bitnet.

Several of these observations were made by John M. Kennedy, Director of the Indiana University Center for Survey Research, in a July 1994 interview. 
The questionnaire asked about frequency of use of computer-based tools: word processing, electronic mail, online library catalogs, the MLA International Bibliography (CD-ROM and online), other journal indexes, and electronic texts. In addition, participants were asked about the major changes and problems they experienced with computer-based tools and the amount of time now spent on inlibrary research, research outside the library, and writing. Questions included highest degree, date received, field of study, current position, field of work, and access to microcomputers and network connections at home and at work.

Three hundred ninety responses were received, 206 from the paper-based survey (a $41 \%$ response rate) and 184 from the electronically-mailed survey (a $37 \%$ response rate).

\section{Analysis of survey responses}

Responses to the electronic and paper surveys differed significantly on many questions. Therefore the following discussion compares the results for the two survey groups while also examining the respondents as a whole.

\section{Characteristics of respondents}

of 367 people who listed the subject in which they received their highest degree, 55\% earned degrees in English; the next most common field of study was comparative literature, with $9 \%$ of respondents. These were followed in order by French and Italian 9\%, German $8 \%$ and Spanish 5\%. In terms of current field of work, English again predominated, with $58 \%$ of respondents; this was followed by French and Italian 10\%, German 8\%, and Spanish 7\%. Although $9 \%$ of respondents reported degrees in comparative literature, only $5 \%$ worked in that field. Table 1 shows the distributions for all respondents and for the paperbased and electronically surveyed groups. There was no significant difference between the two survey groups in terms of major subject of study ( chi square $=8.74,6 \mathrm{df}, \mathrm{p}<0.19$ ) or current field of work (chi square $=$ $2.14,6 \mathrm{df}, \mathrm{p}<0.97)$.

Respondents to the paper-based survey generally completed their schooling earlier than those in the electronic survey. The average date the highest degree was earned is 1982 for the paper-based survey and 1985 for the 
electronic, with a significant difference between the groups (chi square = $12.77,5 \mathrm{df}, \mathrm{p}<\odot .03)$. Respondents to the electronic survey appear to be younger; they include significantly more students and fewer retired/emeritus members (chi square $=30.26,6 \mathrm{df}, \mathrm{p}<0.01$ ). However, there is no significant difference between the groups with respect to the highest degree earned. Tables 2 through 4 show distributions for highest degree earned, date that degree was earned, and academic rank of respondent.

Access to microcomputers and connections to computer networks are shown in Table 5. Nearly all respondents have microcomputers at home (360 of 390 , or 92\%); and 255 (65\%) have telecommunications access from home. Most also have microcomputers at work (256, or 66\%) and 236 (61\%) telecommunications access. There were significant differences between the paper-based and electronic survey, with the electronic survey participants more likely to have microcomputers at home (chi square $=10.85,1 \mathrm{df}, \mathrm{p}<0.01$ ), more likely to have access to external computers from home (chi square $=38.79,1 \mathrm{df}, \mathrm{p}<0.01$ ), and more likely to have computer connections at work (chi square $=18.49,1 \mathrm{df}$, p<0.01); however there was no significant difference between the groups regarding whether or not they had microcomputers at work.

Students and faculty members were not significantly different in having microcomputers or telecommunications connections at home. Faculty members were significantly more likely to have a microcomputer at work (chi square = 54.74, $1 \mathrm{df}, p<0.01$ ) and to have a access to other computers over a modem or network connection from work (chi square $=25.89,1 \mathrm{df}, \mathrm{p}<0.01$ ).

Use of computer-based tools

Word processing was heavily used by almost all respondents, with 383 of 390 (98\%) reporting they use a word processor at least once a week. All respondents to the electronic mail survey and $97 \%$ of respondents to the paper survey were frequent users of word processing. Respondents to the paper survey included one with monthly use, two with use about once a semester, and three who never use a word processor.

Electronic mail was also heavily used, with 301 respondents (78\%) reporting at least weekly use. Not surprisingly, the electronically surveyed group 
differed from those in the paper survey. Comparing weekly e-mail users with those who check in monthly, once a semester, or never, the electronically surveyed group were much more frequent users of e-mail (chi square $=77.54,1$ df $p<0.01)$.

Library online catalogs were used at least once a week by 262 respondents (69\%). Electronically surveyed respondents were significantly more likely to be weekly or monthly users of online catalogs (chi square $=14.02,2 \mathrm{df}$, $\mathrm{p}<0.01)$. Use of the MLA International Bibliography on computer did not differ between the two groups. Over half reported using the MLA International Bibliography at least monthly; many used more than one system, with 154 respondents (39\%) on Wilson CD-ROM followed by SilverPlatter and OCLC'S FirstSearch with 75 respondents (19\%) each. Of the 290 who used the $M L A$ International Bibliography database 64 (22\%) were not sure which version they used. Not surprisingly, students in both survey groups used the MLA International Bibliography significantly more often than faculty members. over one third of all respondents use other journal indexes on a weekly or monthly basis, and two thirds use these indexes at least once a semester. Use of other journal indexes was significantly higher among students in the paperbased survey, but faculty and students used these indexes at similar rates in the electronic mail group.

Electronic texts (Oxford English Dictionary, The Bible, etc.) were used weekly or monthly by 21 (11\%) of those in the paper-based survey and by 48 (26\%) in the electronic survey; this represents significantly more frequent use by respondents to the electronic survey (chi square $=14.89,2 \mathrm{df}, p<0.01$ ). Differences between faculty and student use of electronic texts was not significant overall or within each group.

\section{Changes in research activities}

Respondents were asked to compare current activity with their work three years ago regarding amount of work in libraries, outside libraries, and writing. Most people reported spending less time in the library and more time working outside the library. The electronically surveyed group was much more likely to follow this pattern (chi square $=23.75,2 \mathrm{df}, \mathrm{p}<0.01$ ). Respondents also reported spending more time writing, with no significant difference between 
the two groups. In the open-ended comments some mentioned job changes which had led to changes in allocation of research effort: assuming or escaping administrative responsibilities or taking a job at an institution with less support for computer-based resources.

Regarding how computer-based tools have changed research work, both groups commented most often on the impact of word processing, especially the ability to revise and edit material. Several people commented on the changes this made in their work: "Word processing has increased my incentive to write, since it has simplified and streamlined the editing process;" "I also write my papers on computer. Being a foreign student who is dependent on a proofreader, the computer has facilitated my work tremendously; " and their dependence on word processing: "Long resistant to composing at a computer, I now find myself utterly dependent on word processing and thoroughly grateful for the technology."

The second most frequent comment related to the advantages of being able to do research outside the library: "Online catalogs have allowed me to spend less time in the library -- I can send my RA for what I need." "Doing library searches at home has made research much more a part of my work. It's hard for a single parent to get to the library and this is a great help."

The third-ranked observation related to changes in research methods: "It makes interdisciplinary research much more practical for the individual scholar;" and "To the extent that I've been able to get access to on-line research resources, it's sometimes pushed me to search more thoroughly, and sometimes simply prompted me to look through larger amounts of irrelevant info."

Respondents, especially those surveyed electronically, also commented on the value of e-mail and electronic discussions: "I use e-mail (and interest groups) to make queries and to keep in touch with colleagues at other locations;" and "Many times I allow my fingers to do the walking, i.e., I will query someone I met online about a specific problem, rather than going to the library." 
Several commented on the usefulness of libraries' online catalogs as well as interlibrary loan or other means of access to materials: "Facilitates finding texts or authors not in our card catalog. Helps as well with NOT having to go to other libraries if they do not have a text." "I have used Internet to compare library holdings at libraries throughout the nation."

General time savings were explicitly mentioned by several people, sometimes with the added observation that time saved was now used in other ways:

"Accessing our library from my office has saved time (and frustration!) but when computers are down I'm in a state of panic, as expectation is more work in less time;" "Other than [database access] the most decisive difference (in comparison to the typewriter days) is undoubtedly the way I write and edit my writing with a word processor. I find it more effective as far as the results are concerned; it has made me an even harsher critic of my own writing; it does not necessarily save time overall (one saves time on re-typing things but invests it then in multiple editing) but helps concentrate on some of the tasks more directly concerned with producing good critical prose;" "Love accessing from my desk, saves time and allows me to stay available for colleagues."

\section{Problems in using computer-based tools}

When asked about problems with computer-based resources, access was the major issue, with problems ranging from busy phone lines to the need to sign up for workstations to do CD-ROM searches: "My library at my university has had to drop the CD-ROM MLA bibliography due to its exorbitant arrangements for access;" "The cost of Firstsearch goes way beyond our library budget, so it is being discontinued."

Learning to use the resources ranked second: "I've gone to a million workshops, but still it's hard -- guess I'm not computer oriented!" "The technology changes so quickly that I feel like I have to schedule monthly learning sessions. I have yet to master the information superhighway and don't find elementary instructions readily available;" "I know that there are bulletin boards out there and many library catalogues etc. but I always figure it's going to take me so long to learn it, or that I'm going to mess up." 
Problems with technology were the third major hurdle, including the need to upgrade computers, problems with new versions of word processing software, and system response time. For the group overall, particularly for respondents to the paper-based survey, problems with instruction ranked fourth; these included quality of manuals, online help/tutorials, and human assistants. For the groups surveyed electronically the corresponding problem was humancomputer interaction, notably confusing commands on search interfaces and the lack of standards, as well as problems with vision in reading computer screens, "Sometimes the user interface makes using them tough. They can sometimes take so much time to learn how to use properly that I wonder if I'm always saving that much time;" "The systems differ so widely one has to constantly learn new commands." Respondents also mentioned the MLA International Bibliography in several contexts, lamenting the cost of searching or the need to go to the library to use the CD-ROM version. Other problems mentioned included a feeling of being overwhelmed with options or information and a fear of missing something with so many resources; a concern that searching is less effective and that serendipitous discoveries are lost; and a general sense that more time is needed to learn to use computer-based tools.

A few respondents had strong negative comments about computer-based tools: "[They] are less than satisfactory. One wastes enormous time learning the systems' quirks. Despite its potential advantages, I'm not convinced. I learned more in the library-intensive days;" "One can now spend more time exploring more possibilities, but I'm not sure this leads to better work... Is one a lesser scholar for preferring print materials?"

There were also concerns about not knowing what might be available, about the lack of appropriate databases or electronic texts for specific areas of research, and about the reliability of computer-based tools. Others regretted the loss of browsing with computer-based searching or felt overloaded with so many resources available.

\section{Comparison with 1990 MLA survey}

Huber's (1993) report of the 1989-90 MLA membership survey provides a particularly useful benchmark for studying adoption of computer tools. The 
MLA Membership Survey (which will be referred to here as the 1990 survey) "was designed to give members the opportunity to express their views on a spectrum of issues concerning the association, the profession and the field. Several of the survey questions dealt with aspects of computer use." (p.1.) Our paper-based survey (which will be referred to here as the 1994 survey) used the same technologies (paper and postal service) and was sent to a randomly selected sample of the MLA membership. The demographics of the 1990 survey and the 1994 survey are similar: most respondents were full professors, most had earned degrees in English, with French and Italian, Spanish and Portuguese, German, and Comparative Literature each accounting for 5 to $10 \%$ of respondents. Most had completed their highest degree within the past 10 years.

The four years between the surveys witnessed a major shift in the use of computer-based tools by humanities scholars. In 1990, $90 \%$ of respondents had access to a computer but only $79 \%$ had microcomputers at home; by 1994 , $88 \%$ had home microcomputers. Computers were used heavily for word processing. In 1990, 95\% reported using computers to prepare manuscripts; similarly in 1994, 97\% reported using word processing at least once a week. In 1990 only 46\% reported they had access to computer networks and only $18 \%$ used electronic mail; by $1994,74 \%$ had connections at home or at work or both, with $60 \%$ using electronic mail weekly or more often. In 1990, $28 \%$ reported doing database or literature searching; by 1994, 54\% used computers for searching MLA or other indexes at least monthly and $86 \%$ used libraries' online catalogs as often. Figure 1 compares these rates of use of computer-based tools.

\section{Summary and conclusion}

Clearly computer-based tools are being used increasingly by humanities scholars. Word processing in particular is used almost universally, and it influences the nature of scholarly writing. Electronic mail, "listservs," and news groups are important ways of communicating, especially for the electronic mail survey group. This is a major change from the stereotype of the isolated scholar, and also a contrast with Hopkins'(1989) findings that humanities scholars do not rely on informal communication with other scholars. (p. 114) Bibliographic databases also are employed extensively, especially by students. Apparently technical advances, which have brought down the cost to the user, 
have made possible considerable increases in CD-ROM use as well as online searching. Humanities scholars also use online catalogs extensively, with remote access proving especially valuable. Increased access to and use of bibliographic information in databases and catalogs raises concerns about access to the documents themselves, for example through document delivery and full text databases. As of 1994, electronic full texts such as The oxford English Dictionary or The Bible were used by relatively few humanities scholars, with approximately equal levels of use by students and faculty.

The nature of humanities research is changing, with less work in library buildings. Apparently the virtual library is coming into being, at least for bibliographic work preceding the study of texts. Computer-based tools are introducing new problems for scholars as more effort is needed to learn how to use the resources, to understand the instruction available, and to adapt to a variety of systems and interfaces. Access to the resources is also a concern, as are technical barriers and problems of cost and reliability of continually evolving computer-based resources.

It should be noted that electronic surveys may be appealing in terms of delivery costs; however, they can produce misleading results at this historical (dis)juncture in the use of computer-based tools. Such surveys currently should be considered representative of only that segment of the population with skill and interest in electronic communication. To do otherwise risks creating another "Dewey Defeats Truman" story, where the outcome of the 1948 election was forecast from a telephone poll when many voters did not have telephones. 


\section{References}

Adams, J.A. \& Bonk, S.C. (1995). Electronic information technologies and resources: use by university faculty and faculty preferences for related library services. College \& research libraries 56, 119-131.

Baron, N.S. (1985). Humanists among the CRT's: the problem of a method in the humanities. Liberal education 71, 251-263.

Cool, C. (1993). Information retrieval as symbolic interaction: examples from humanities scholars. Proceedings of the Annual Meeting of the American Society for Information Science 56, 274-277.

Dillman, D.A. (1978). Mail and telephone surveys. New York: Wiley.

Hopkins, R. (1989). The information seeking behaviour of literary scholars. Canadian library journal 46, 113-115.

Huber, B. (1993). "Computer use among MLA members: Selected findings from the 1990 membership survey," February 1993 (revised March 1993). New York: Modern Language Association of America.

Katzen, M. (1985). Technology and communication in the humanities: training and services in universities and polytechnics in the UK. London: British Library.

Krausse, S.C. \& Etchingham, J.B., Jr. (1986). The humanist and computerassisted library research. Computers and the humanities, 20, 87-96.

Pandit, I. (1992). "Informal communication in the humanities: a qualitative inquiry. Ph.D. dissertation, University of Illinois at Urbana-Champaign. 
McClamroch, J., Stein, L.L. \& Williamson, E. (1991). MLA on CD-ROM: end-users respond. Reference services review, 19, 81-86.

Rogers, E.M. (1971). Communication of innovations, 2d ed. New York: Free Press.

Siegfried, S., Bates, M.J. Wilde, D.N. (1993). A profile of end-user searching behavior by humanities scholars: the Getty online Searching Project report no. 2. Journal of the American Society for Information Science, 44, 273-291.

Sievert, D. \& Sievert, M. (1989). Philosophical research: report from the field. In Humanists at work: papers presented at a symposium held at the University of Illinois at Chicago, 79-94.

Sproull, L.S. (1986). Using electronic mail for data collection in organizational research. Academy of management journal 29, 159-169.

Stone, S. (1982). Humanities scholars: information needs and uses. Journal of documentation 38, 292-313.

Stover, M. ed. (1992) Electronic information for the humanities. Library trends, 40 (entire issue).

Tibbo, H.R. (1991). Information systems, services, and technology for the humanities. Annual review of information science and technology 26, 287-346.

Walsh, J.P., Kiesler, S., Sproull, L.S., Hesse, B.W. (1992). Self-selected and randomly selected respondents in a computer network survey. Public opinion quarterly 56, 241-244.

Watson-Boone, R. (1994). The information needs and habits of humanities scholars. $R Q 34,203-216$.

Wiberley, S.E., Jr. (1991). Libraries and the humanities. ACLS newsletter 3, 11-12. 
Shaw - 16

Wiberley, S.E., Jr. \& Jones, W.G. (1994). Humanists Revisited: a longitudinal look at the adoption of information technology. College \& research libraries 55, 499-509. 


\section{Table 1. Subject area of highest degree and current work}

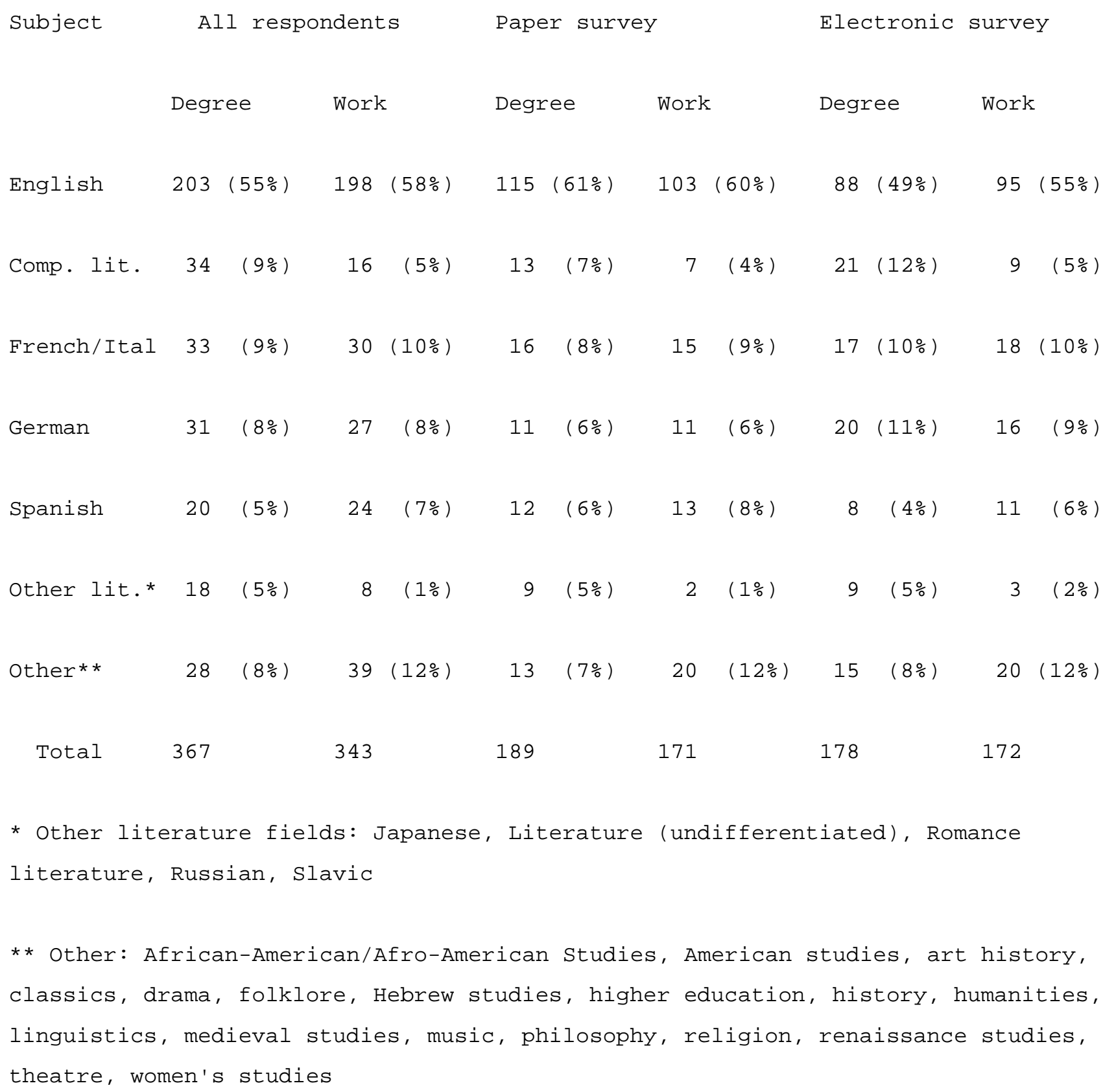


Table 2. Highest degree earned

\begin{tabular}{|c|c|c|c|}
\hline & All respondents & Paper survey & Electronic survey \\
\hline Bachelor's & $9 \quad(2 \%)$ & $(1 \%)$ & $(4 \%)$ \\
\hline Master's & $96(26 \%)$ & $45(23 \%)$ & $52(29 \%)$ \\
\hline$A B D$ & $29 \quad(8 \%)$ & $(8 \%)$ & $(7 \%)$ \\
\hline Ph.D. & $235(63 \%)$ & $127(65 \%)$ & $108(60 \%)$ \\
\hline other & $5 \quad(1 \%)$ & $(3 \%)$ & $(1 \%)$ \\
\hline Total & 376 & 195 & 181 \\
\hline
\end{tabular}

Table 3. Year highest degree earned

All respondents Paper survey Electronic survey

$\begin{array}{lllll}1939-69 & 40(11 \%) & 29(15 \%) & 11 \quad(6 \%) \\ 1970 s & 66(18 \%) & 39(20 \%) & 27(15 \%) \\ 1980-84 & 38(10 \%) & 15 & (8 \%) & 23(13 \%) \\ 1985-89 & 64(17 \%) & 29(15 \%) & 35 \quad(20 \%) \\ 1990-92 & 89(24 \%) & 42(22 \%) & 48(27 \%) \\ 1993-95 & 70(19 \%) & 38(20 \%) & 32(18 \%) \\ \text { Total } & 368 & 192 & 176\end{array}$


Table 4. Rank

\begin{tabular}{|c|c|c|c|}
\hline All & respondents & Paper survey & Electronic survey \\
\hline Student & 109 (29\%) & 42 (22\%) & 67 (37\%) \\
\hline Asst. prof. & $64(17 \%)$ & $27(14 \%)$ & 37 (20\%) \\
\hline Assoc. prof. & 59 (16\%) & $28(15 \%)$ & $31(17 \%)$ \\
\hline Professor & 72 (19\%) & 41 (21\%) & $31(17 \%)$ \\
\hline Retired & $16 \quad(4 \%)$ & $15 \quad(8 \%)$ & $1 \quad(1 \%)$ \\
\hline other & $54(14 \%)$ & 38 (20\%) & $16 \quad(8 \%)$ \\
\hline Total & 374 & 191 & 183 \\
\hline All & respondents & Paper survey & Electronic survey \\
\hline Home micro & $360 \quad(92 \%)$ & 181 (88\%) & 179 (97\%) \\
\hline Home connection & $255(65 \%)$ & 105 (51\%) & $150(82 \%)$ \\
\hline Work micro & $256(66 \%)$ & 127 (62\%) & $129(70)$ \\
\hline Work connection & $236(61 \%)$ & $104 \quad(50 \%)$ & $132(72 \%)$ \\
\hline
\end{tabular}


Table 6. Use of electronic mail

All respondents Paper survey Electronic survey

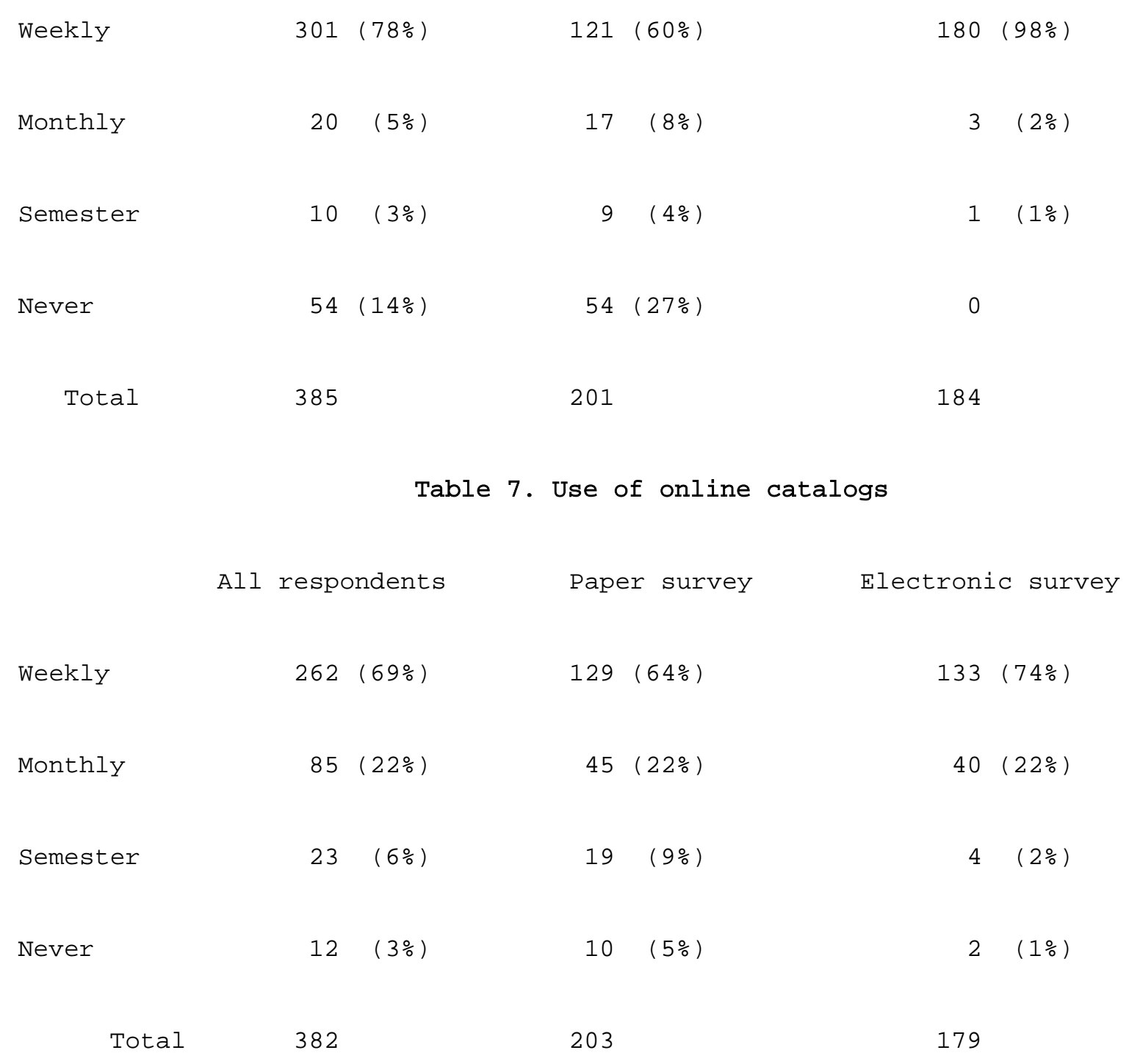


Table 8. Use of MLA International Bibliography on CD-ROM or online All respondents Paper survey Electronic survey

\begin{tabular}{|c|c|c|c|c|c|}
\hline Weekly & & 44 & $(12 \%)$ & $26(13 \%)$ & $18(10 \%)$ \\
\hline Monthly & & 160 & $(42 \%)$ & $73(36 \%)$ & $87(48 \%)$ \\
\hline Semester & & 86 & $(23 \%)$ & $51(26 \%)$ & $35(19 \%)$ \\
\hline Never & & 92 & $(24 \%)$ & $51(26 \%)$ & $41(23 \%)$ \\
\hline \multirow[t]{2}{*}{ Total } & & 382 & & 201 & 181 \\
\hline & All & resp & ndents & Paper survey & Electronic survey \\
\hline Weekly & & 41 & $(11 \%)$ & $21(11 \%)$ & $20(11 \%)$ \\
\hline Monthly & & 103 & $(27 \%)$ & $42(21 \%)$ & $61(34 \%)$ \\
\hline Semester & & 116 & $(30 \%)$ & $66(33 \%)$ & $50(27 \%)$ \\
\hline Never & & 121 & $(32 \%)$ & $70(35 \%)$ & $51(28 \%)$ \\
\hline Total & & 381 & & 199 & 182 \\
\hline
\end{tabular}




\section{Table 10. Use of electronic texts}
All respondents
Paper survey
Electronic survey

\begin{tabular}{|c|c|c|c|}
\hline Weekly & $34 \quad(9 \%)$ & $11 \quad(6 \%)$ & $23(13 \%)$ \\
\hline Monthly & $(9 \%)$ & $(5 \%)$ & $25(14 \%)$ \\
\hline Semester & $50 \quad(13 \%)$ & 29 (15\%) & $21(12 \%)$ \\
\hline Never & $255(68 \%)$ & $142(74 \%)$ & $113(62 \%)$ \\
\hline Total & 374 & 192 & 182 \\
\hline
\end{tabular}

Table 11. Responses to question on changes in research activity, ranked by frequency of occurrence
All respondents
Paper survey
Electronic survey
word processing (130)
work outside lib. (95)
research methods (86)
e-mail/Internet (85)
online catalogs (68)
time saving (46)
word processing (66)
research methods (46)
work outside lib. (41)
online catalogs (31)
e-mail/Internet (24)
time saving (23)
word processing (64)
work outside lib. (54)
e-mail/Internet (45)
research meth. (38)
online catalogs (37)
time saving (23) 
Table 12. Responses to question on problems with computer-based tools, ranked by frequency of occurrence

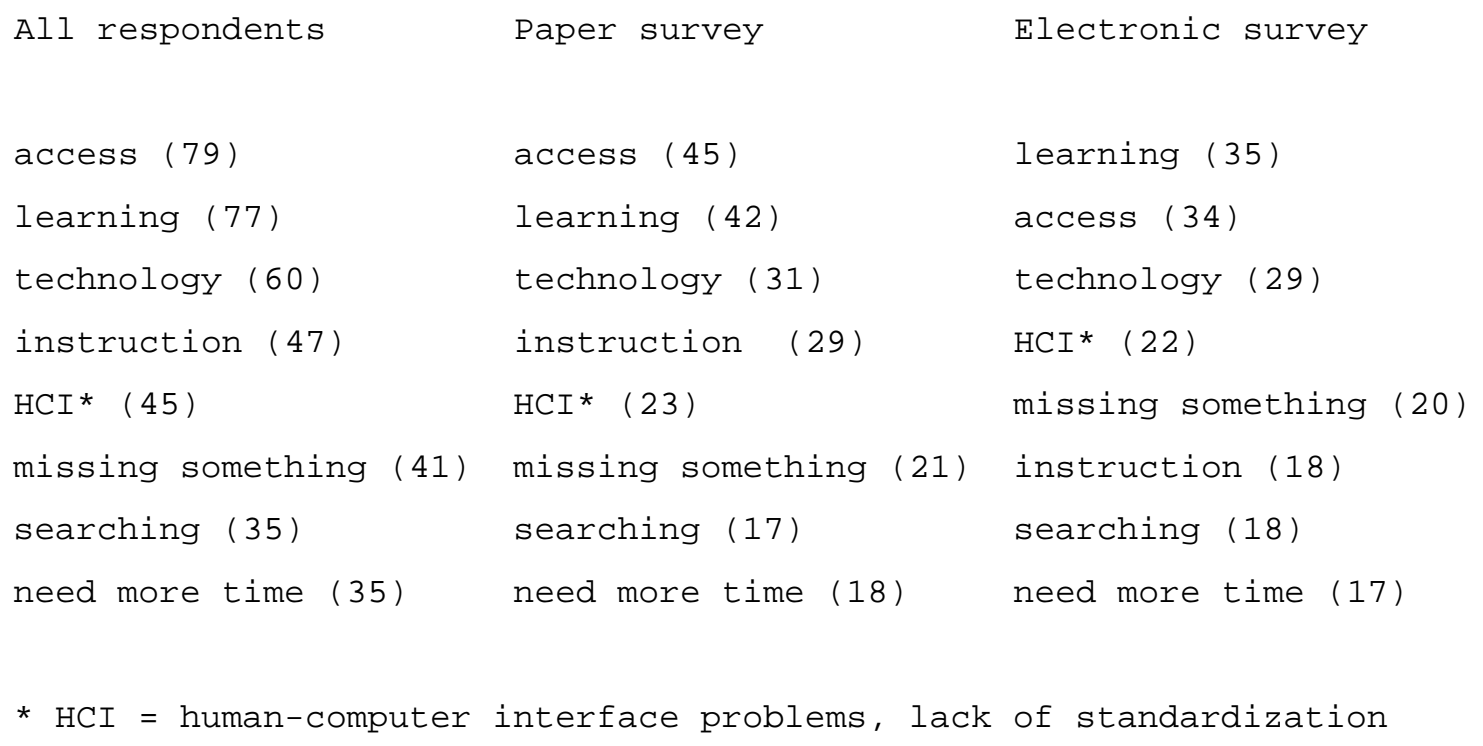

* $\mathrm{HCI}=$ human-computer interface problems, lack of standardization 